\title{
Possible Effect of Extended Use of Hormonal Contraception on Increased Levels of Antiphospholipid Antibodies in Infertile Women
}

\author{
Mögliche Auswirkung der Langzeiteinnahme hormoneller Empfängnisverhütungsmittel \\ auf den erhöhten Antiphospholipid-Antikörper-Spiegel bei unfruchtbaren Frauen
}

Authors

Affiliations
Z. Ulcova-Gallova ${ }^{1,2}$, K. Bibkova ${ }^{1}$, Z. Micanova ${ }^{1}$, P. Losan ${ }^{1}$, K. Babcova ${ }^{2}$

${ }^{1}$ Genetics-Pilsen, Pilsen, Czech Republic

${ }^{2}$ Dept. Gynecology Obstetrics, Charles University, Pilsen, Czech Republic
Key words

infertility

- hormonal contraception

- antiphospholipid antibodies

- antiphospholipid syndrome

Schlüsselwörter

- Infertilität

- hormonelle Empfängnisverhütung

- Antiphospholipid-Antikörper

- Antiphospholipid-Syndrom

\section{received 27.3.2014 \\ revised $\quad 5.2 .2015$ \\ accepted 6.2.2015}

\section{Bibliography}

DOI http://dx.doi.org/

10.1055/s-0035-1545869

Geburtsh Frauenheilk 2015; 75 :

251-254 @ Georg Thieme

Verlag KG Stuttgart · New York . ISSN 0016-5751

\section{Correspondence}

Prof. Zdenka Ulcova-Gallova

Genetics-Pilsen

Parkova $11 \mathrm{~A}$

32600 Pilsen

Czech Republic

ulcova-gallova@email.cz

\section{Abstract \\ $\nabla$}

Purpose: Increased levels of antiphosholipid antibodies (aPLs) are associated with the autoimmune disorder antiphospholipid syndrome (APS) and are known to play a role in infertility. We investigated the possible effect of prolonged use of hormonal contraception (HC) on autoimmunity after discontinuing $\mathrm{HC}$ in women with infertility problems.

Material and Methods: We analyzed hormonal status including ovulation and the humoral autoimmune response to eight phospholipids detected by ELISA in 1190 infertile women aged 21-46 (mean age: 29.3) years.

Results: Long-term HC did not affect ovulation, but in the absence of ovulation $\mathrm{HC}$ masked the hormonal disorders. The majority of patients taking $\mathrm{HC}$ for more than 10 years with fertility failure had significantly higher levels of aPLs of the IgG isotype against phosphatidylinositol and phosphatidylserine $(p>0.001)$ than against $\beta 2$-glycoprotein $\mathrm{I}$ and annexin $\mathrm{V}$.

Discussion: Thus, high levels of aPLs are significant for the anticoagulant treatment before and during pregnancy to prevent pregnancy loss.

\section{Introduction}

$\nabla$

Hormonal contraception (HC) is a birth control method that prevents ovulation by suppressing gonadotropins and changing the properties of cervical mucus. The most common combined con-

\section{Zusammenfassung \\ $\nabla$}

Zielsetzung: Das erhöhte Auftreten von Antiphospholipid-Antikörpern im Blut ist mit der Autoimmunerkrankung Antiphospholipid-Syndrom (APS) assoziiert und spielt bekanntlich eine Rolle bei Infertilität. In Frauen mit Fertilitätsproblemen wurde die mögliche Auswirkung der Langzeiteinnahme hormoneller Empfängnisverhütungsmittel auf die Autoimmunität untersucht, die auch nach Absetzen des Mittels fortbesteht.

Methoden: In 1190 unfruchtbaren Frauen im Alter von 21-46 (Durchschnittsalter: 29,3) Jahren wurden Hormonstatus und Eisprung sowie die durch ELISA ermittelte humorale Immunreaktion auf 8 Phospholipide untersucht.

Ergebnisse: Die Langzeiteinnahme hormoneller Empfängnisverhütungsmittel hatte keine Auswirkung auf den Eisprung, aber bei Ausbleiben des Eisprungs hat die hormonelle Empfängnisverhütung die Hormonstörung überdeckt. Die Mehrheit der Patientinnen mit Fertilitätsproblemen, die Hormonpräparate zur Empfängnisverhütung über einen Zeitraum von mehr als 10 Jahren einnahmen, wiesen signifikant höhere Antiphospholipid-Antikörper-Spiegel des IgG-Isotyps gegen Phosphatidylinositol und Phosphatidylserin $(\mathrm{p}>0,001)$ auf als gegen $\beta 2$-Glykoprotein I und Annexin V.

Diskussion: Hohe Antiphospholipid-AntikörperSpiegel erweisen sich also als signifikant für die antikoagulatorische Therapie vor und während der Schwangerschaft, um einem frühzeitigen Ende der Schwangerschaft vorzubeugen.

traceptives contain the both hormones, estrogen and progestin. HC has various well-known side effects such as bleeding, elevated liver tests, increased risk of cardiac disease, psychological and sexual changes, and deep vein thrombosis $[1,2]$. Although the history of HC commenced in 1921, 
Table 1 Fertility data of 1190 patients after HC use with analysis of ovulation at 6 months after termination of HC.

\begin{tabular}{|lcccc} 
& Group 1 & Group 2 & Group 3 & Subgroup 4 from group 3 \\
N & 220 & 221 & 749 & 213 \\
\hline Age range (mean) & $20-39(28.7)$ & $21-44(27.8)$ & $22-46(31.4)$ & $25-46(35.6)$ \\
\hline Complications & & & & \\
\hline - RPL & $2(0.9 \%)$ & $45(20.4 \%)$ & $65(8.7 \%)$ & $4(1.9 \%)$ \\
\hline - Fetal loss & $1(0.4 \%)$ & $4(1.8 \%)$ & $6(0.8 \%)$ & 0 \\
\hline - IVF failure & $64(29.0 \%)$ & $120(54.3 \%)$ & $540(72.1 \%)$ & $190(89.2 \%)$ \\
\hline - NP & $153(69.7 \%)$ & $46(20.8 \%)$ & $134(17.9 \%)$ & $19(8.9 \%)$ \\
\hline Delivery before pregnancy failure & 0 & $6(2.7 \%)$ & $4(0.5 \%)$ & 0 \\
\hline Physiological ovulation & $202(92 \%)$ & $102(46 \%)$ & $157(21 \%)$ & $23(11 \%)$ \\
\hline
\end{tabular}

RPL - repeated pregnancy loss

$\mathrm{NP}$ - never pregnant

with studies done in a rabbit model [3], the first combined HC was used in Great Britain in 1957. Since then, a large number of women of reproductive age have used $\mathrm{HC}$ with or without side effects [4]. Heterogeneous autoantibodies specific for negatively charged membrane phospholipids were detected in 1906 by Wassermann [5] in patients with syphilis, and immunochemically isolated by Pangborn [6]. Antiphospholipid antibodies (aPLs) are detectable in almost $80 \%$ of patients with autoimmune disease. Furthermore, they are also present in patients with reproductive failure, with a wide range of potential complications before spontaneous and/or in vitro fertilization (IVF), during problems encountered in early or late pregnancy (including spontaneous miscarriage, missed abortion, fetal death, intrauterine growth retardation, prematurity, and preeclampsia), and especially in primary or secondary antiphospholipid syndrome (APS) [7-10]. Antiphospholipid antibodies can interfere with normal conception by binding to phospholipids in the ovary, thus preventing formation and release of a functional ovum, or in normal fertilization by binding to the surface of either the ova or the spermatozoa with cytoplasmic, mitochondrial, endothelial and trophoblast epithelial cell membranes and platelets $[11,12]$. aPLs can negatively influence the remarkable tolerance mediated by complex immunoregulatory mechanisms which exists between mother and fetal trophoblast $[13,14]$. Fertility problems caused by microthrombosis of the utero-placental vasculature are the result of endothelial cell activation, inhibition of protein complex formation and fibrinolysis, and annexin $\mathrm{V}$ displacement $[15-17,19,20]$; other mechanisms for non-thrombotic fetal damage have been also considered [16$18,21]$. During our routine practice in counseling infertile couples, we observed an increase in serum autoantibodies against phospholipids in oral contraceptive users who decided to discontinue HC and attempt to conceive. Problems with fertility were evident (no spontaneous pregnancy and unsuccessful IVF, often combined with spontaneous miscarriage or missed abortion). The aim of our present study was to establish a screening profile for all aPLs (aPLs of the IgG, IgM, IgA isotypes specific for cardiolipin, phosphatidyl (ph)-serine, ph-ethanolamine, ph-inositol, phglycerol, phosphatidic acid, annexin V and $32-\mathrm{GPI}$ ) in selected infertile women with reproductive failure and to evaluate the possible side effects of prolonged HC on their autoimmunity.

\section{Material and Methods}

$\nabla$

\section{Patients}

The study group consisted of 1190 patients, aged 21-46 years (mean age: 29.3) ( Table 1) who were referred for pregnancy planning to the Division for Infertility and Immunology of Reproduction at the Department of Obstetrics and Gynecology, Charles University and Faculty Hospital, Pilsen, Czech Republic between 2008 and 2013. All women of reproductive age were divided into three main groups according to the use and the length of $\mathrm{HC}$ intake ( Table 1 ). The 1 st group included 220 women who had never used $\mathrm{HC}$ and served as a control group. The 2nd group (221 women) were on HC for a maximum period of two years, and the 3rd group included 749 patients who had used HC for 3 to 20 years. We also studied a 4th subgroup, selected from the 3rd group of infertile women, who had taken HC for 10 and more years. The common goal of all patient groups was successful conception after repeated fertility failures. Their partners had normal spermiograms evaluated according to WHO criteria [22]. Medical history indicated a good health status for both partners. Blood samples were obtained from each woman between 7:0010:00 a. $\mathrm{m}$. All obtained serum samples were frozen and stored at $-18^{\circ} \mathrm{C}$ in our serum bank. All sera were screened for the presence of eight aPLs. No female patient had a history of vascular thrombosis, thrombocytopenia, autoimmune or infectious disease.

The study was approved by the local research ethics committee of the Charles University Medical Faculty Hospital, Pilsen, Czech Republic. Written informed consent was obtained from all female participants.

\section{Antiphospholipid antibodies (aPLs)}

Enzyme-linked immunosorbent assay (ELISA) was used for the detection of aPLs of the IgG, IgA and IgM isotypes against ph-serine, ph-ethanolamine, ph-inositol, ph-glycerol, phosphatidic acid, annexin V, $\beta 2-$ GPI and cardiolipin levels as previously described [19]. Briefly, serially diluted sera were incubated with plates coated with highly purified phospholipids. After washing the plates, anti-human immunoglobulins conjugated to horseradish peroxidase were incubated with the antigen-antibody complex. Unbound conjugate was then washed away. Addition of an enzyme substrate generated an enzymatic colorimetric reaction, which was stopped by diluted acid. The intensity of the color, which was directly proportional to the concentration of antibodies, was measured photometrically.

\section{Statistical analysis}

Statistical analysis of all laboratory results was done using MannWhitney U-Test for Independent Samples in Statistics for Windows, Version 22.0 (IBM Corp., Armonk, NY, USA), with p-values $\leq 0.05$ considered statistically significant. 
Table 2 Analysis of antiphospholipid antibodies in women without and with long-term HC use (2008-2013).

\begin{tabular}{|c|c|c|c|c|c|c|}
\hline & & Group 1 & Group 2 & Group 3 & Subgroup 4 from Group 3 & p-value \\
\hline \multicolumn{2}{|l|}{$\mathrm{N}$} & 220 & 221 & 749 & 213 & \\
\hline \multicolumn{2}{|l|}{ Mean age (years) } & 28.7 & 27.8 & 31.4 & 35.6 & NS \\
\hline \multicolumn{2}{|c|}{ Presence of antiphospholipid antibodies against: } & $56(25 \%)$ & $95(43 \%)$ & $588(78.5 \%)$ & $189(89 \%)$ & 0.001 \\
\hline \multirow[t]{2}{*}{ - Cardiolipin } & $\lg G$ & $3(1.4 \%)$ & $4(1.8 \%)$ & $18(2.4 \%)$ & $5(2.3 \%)$ & NS \\
\hline & $\lg M$ & $2(0.9 \%)$ & $3(1.3 \%)$ & $0(0 \%)$ & $5(2.3 \%)$ & NS \\
\hline \multirow[t]{2}{*}{ - Ph-inositol } & $\lg G$ & $54(24.5 \%)$ & $58(26.2 \%)$ & $273(36.4 \%)$ & $212(99.5 \%)$ & 0.001 \\
\hline & $\lg M$ & $2(0.9 \%)$ & $1(0.4 \%)$ & $5(0.6 \%)$ & $5(2.0 \%)$ & NS \\
\hline \multirow[t]{2}{*}{ - Ph-serine } & $\lg G$ & $19(8.6 \%)$ & $21(9.5 \%)$ & $321(42.8 \%)$ & $208(98.0 \%)$ & 0.001 \\
\hline & $\lg M$ & $0(0 \%)$ & $4(1.8 \%)$ & $8(1.0 \%)$ & $6(2.8 \%)$ & NS \\
\hline \multirow[t]{2}{*}{ - Ph-glycerol } & $\lg G$ & $11(5.0 \%)$ & $8(3.6 \%)$ & $57(7.60 \%)$ & $41(19.0 \%)$ & NS \\
\hline & $\lg M$ & $0(0 \%)$ & $4(1.8 \%)$ & $12(1.6 \%)$ & $8(4.0 \%)$ & NS \\
\hline \multirow[t]{2}{*}{ - Ph-ethanolamine } & $\lg G$ & $12(5.4 \%)$ & $8(3.6 \%)$ & $61(8.1 \%)$ & $51(24.0 \%)$ & 0.01 \\
\hline & $\lg M$ & $1(0.4 \%)$ & $2(0.9 \%)$ & $16(2.0 \%)$ & $9(4.2 \%)$ & NS \\
\hline \multirow[t]{2}{*}{ - $\beta 2$-GPI } & $\lg G$ & $5(2.3 \%)$ & $20(9.0 \%)$ & $39(5.2 \%)$ & $29(13.6 \%)$ & 0.01 \\
\hline & $\lg A$ & $0(0 \%)$ & $1(0.4 \%)$ & $10(1.3 \%)$ & $3(1.4 \%)$ & NS \\
\hline \multirow[t]{2}{*}{ - Phosphatidic acid } & $\lg G$ & $16(7.2 \%)$ & $8(3.6 \%)$ & $60(8.0 \%)$ & $23(10.8 \%)$ & NS \\
\hline & $\lg M$ & $0(0 \%)$ & $0(0 \%)$ & $0(0 \%)$ & $3(1.4 \%)$ & NS \\
\hline - Annexin V & $\lg G$ & $5(2.3 \%)$ & $9(4 \%)$ & $37(4.9 \%)$ & $32(15.0 \%)$ & 0.01 \\
\hline
\end{tabular}

NS - not significant

Group 1 - not on HC; Subgroup 4 (HC use of between 10 years and 20 years)

\section{Results}

\section{$\nabla$}

- Table 1 shows the medical history of 1190 women before immunological examination. Long-term use of $\mathrm{HC}$ interferes with physiological ovulation but also depends on the age of patients. Normal ovulation was present in $92 \%$ of women who never used HC. In the 2nd and 3th groups with long-term HC use, ovulation was restored in $46 \%$ (2nd group), $21 \%$ ( 3 rd group), and $11 \%$ in the 4th subgroup ( Table 1).

Serum samples from 1190 infertile patients were evaluated for antibodies of the IgG, IgM and IgA isotypes specific for eight different phospholipids. We assessed individual aPLs with respect to their specificity, prevalence (given as a percentage) and significance. The results in Table 2 showed overall positivity for aPLs in $78 \%$ of women who used HC for more than 2 years ( $p \leq 0.001$ ) and also demonstrated significantly higher levels of antibodies against ph-inositol and ph-serine ( $\mathrm{p} \leq 0.001)$. The antibodies predominantly present were of the IgG isotype. Results also demonstrated significant differences between patients who never used $\mathrm{HC}$ (group 1) and those who had used HC for more than 10 years (subgroup 4). Increased aPLs positivity was found in $89 \%$ of patients, with higher levels of aPLs against ph-inositol ( $\mathrm{p} \leq 0.001)$, ph-serine ( $p \leq 0.001)$, ph-ethanolamine ( $p \leq 0.01)$, $\beta 2$-GPI and annexin $\mathrm{V}(\mathrm{p} \leq 0.01)$. Our detailed analysis suggests that the prevalence of positive levels of aPLs against five different phospholipids was much higher in the group of HC users than in non-HC users, where we found only very low levels of such antibodies.

\section{Discussion}

\section{$\nabla$}

In a normal pregnancy, the mother is exposed to a great number of autoimmune and alloimmune antigens which modulate her immune activities. The immunologic mechanisms of pregnancy loss have been the subject of several reviews e.g. [7-9, 12,13,16$18,20,23]$. This paper summarizes our experience in a longtermed study of women who used HC for more than ten years and displayed significantly increased levels of IgG aPLs, predom- inantly against ph-inositol, ph-serine, ph-ethanolamine, $\beta 2-\mathrm{GPI}$, and annexin $\mathrm{V}$. These autoantigens contribute to the pathogenesis of pregnancy failure through multiple mechanisms in which the central feature could be thrombosis and/or microthrombosis [23]. We did not find information on these findings in the literature. However, the effects of estrogen and progesterone in autoimmune diseases such as systemic lupus erythematosus (SLE) have been previously described [24-30]. Therefore, we aimed to determine whether HC played a role in the elevation of autoimmune factors such as aPLs which contribute to fertility failure. It is well known $[29,30]$ that estrogens have both pro-inflammatory and anti-inflammatory effects, with certain immunomodulatory and immunosuppressive activities enhancing the proliferation and activation of B-cells. Estrogen administration has the potential effect to exacerbate autoimmune processes and can also increase the risk of thrombosis, especially in women positive for aPLs. Our patients had taken oral combined hormonal contraceptives with different concentrations of the biologically active synthetic estrogen (ethinyl estradiol) and one of the 17-alpha ethinyl analogs of 19-nortestosterone as the progesterone component. However, it is not known which drug combination led to the induction of aPLs. Thromboembolism is a major complication of $\mathrm{HC}$, the risk being further increased by the presence of positive autoimmune factors such as lupus coagulant and aPLs [15]. Could HC be the reason for the long-term effects of exogenous estrogen and progesterone through the impact on female autoimmunity? Our study focused on screening for aPLs positivity and determination of aPLs profiles in women with varying lengths of HC use. Although we also considered other causes of fertility problems (through the evaluation of gynecological and endocrinological information, reproductive immunology and genetics), the results of the aPLs panels were clear. A minority of women who did not use HC but had infertility problems also displayed certain immunological abnormalities such as the presence of aPLs antibodies. Although the current classification of APS is based only on positive identification using one or more of three standardized laboratory assays (anti-cardiolipin antibodies, lupus anti-coagulant, and anti- $\beta 2$-GPI according to the report of 
aPLs congresses [7,31]), it is clear that other antiphospholipid antibodies may also play an important role in pregnancy failure. To determine the immunological cause of infertility this definition is insufficient. This is the reason why our laboratory, which specializes in reproductive immunology, uses a wider range of aPLs. Results generated suggest that women with previous longterm use of HC have significantly increased levels of aPLs, especially of the IgG isotype, against ph-inositol and ph-serine, and that these levels are higher than those against $32-$ GPI, and annexin V. Based on our results and extensive experience with human infertility and reproductive immunology, we stress that prolonged use of HC is likely to affect female autoimmunity through the induction of various autoantibodies such as aPLs. Immune response could be also associated with aging, particularly in older patients [32-34], but none of our patients were elderly; in all groups, only a minority of patients with proven anovulation and higher number of positives for aPLs were aged 40 or older. We speculate that the long-term intake of a combination of artificial hormones such as those present in HC and patient age of more than 35 years could influence hormonal and immunological responses.

\section{Conclusion}

\section{$\nabla$}

We suggest that prolonged HC use represents a new and significant risk factor for immunological reproductive failure [33,34]. The presence of high levels of aPLs could alert clinicians, prompting them to initiate timely anticoagulant treatment to prevent APS.

\section{Acknowledgements \\ $\nabla$}

Supported by grant MSM 0021620812 and by the Charles University Research Fund (project number P36).

\section{Conflict of Interest}

$\nabla$

None declared.

\section{References}

1 Cameron ST, Glasier A. Chapter 40. In: Dewhurst's Textbook of Obstetrics \& Gynaecology. 8th ed. London: Wiley-Blackwell; 2012: 495-512

2 Sulak PJ, Scow RD, Preece $C$ et al. Hormone withdrawal symptoms in oral contraceptive users. Obstet Gynecol 2000; 95: 261-266

3 Müller-Jahncke WD. [Ludwig Haberlandt (1885-1932) and the development of hormonal contraception]. Z Gesamte Inn Med 1988; 43: 420-422

4 Perone N. The history of steroidal contraceptive development: the progestins. Perspect Biol Med 1993; 36: 347-362

5 Wasserman A. Über die Entwicklung und den gegenwärtigen Stand der Serodiagnostik gegenüber Syphilis. Berlin: Klin Wochenschr 1907; 44: 1599-1605

6 Pangborn MC. A new serologically active phospholipids from beef heart. Proc Soc Exp Biol Med 1941; 48: 484-486

7 Cervera R, Piette JC, Font J et al. Antiphospholipid syndrome: clinical and immunologic manifestations and patterns of disease expression in a cohort of 1,000 patients. Arthr Rheumat 2002; 46: 1019-1027

8 Ruffatti A, Del Ross T, Ciprian M et al. Risk factors for a first thrombotic event in antiphospholipid antibody carriers: a prospective multicentre follow-up study. Ann Rheum Dis 2011; 70: 1083-1086
9 Shoenfeld $Y$, Blank M. Autoantibodies associated with reproductive failure. Lupus 2004; 9: 643-648

10 Roubey RA. Immunology of the antiphospholipid antibody syndrome. Arthritis Rheum 1996; 39: 1444-1454

11 Gleicher N, El-Roeity A, Confino E et al. Reproductive failure because of autoantibodies unexplained infertility and pregnancy wastage. Am J Obstet Gynecol 1989; 160: 1376-1380

12 Chaouat G. Regulation of cellular immune response from the mother to the paternal antigens of the conceptus. Prog Clin Biol Res 1981; 70: 137-144

13 Hemberger $M$. Immune balance at the foeto-maternal interface as the fulcrum of reproductive success. J Reprod Immunol 2013; 97: 36-42

14 McNeil HP, Chesterman CN, Krilis SA. Immunology and clinical importance of antiphospholipid antibodies. Adv Immunol 1991; 49: 193280

15 Cervera R, Balasch J. Bidirectional effects on autoimmunity and reproduction. Human Reprod Update 2008; 14: 359-366

16 Carp JA, Selmi C, Shoenfeld Y. The autoimmune bases of infertility and pregnancy loss. J Autoimmun 2012; 38: 266-274

17 Ulcova-Gallova Z. Repeated miscarriages in patients with antiphospholipid syndrome and subjected to in vitro fertilization: the importance of preimplantation genetic diagnosis. Lupus 2012; 21: 744-746

18 Ulcova-Gallova Z, Krauz V, Novakova P et al. Anti-phospholipid antibodies against phosphatidylinositol, and phosphatidylserine are more significant in reproductive failure than antibodies against cardiolipin only. Am J Reprod Immunol 2005; 54: 112-117

19 Ulcova-Gallova Z, Mukensnabl P, Hadravska $S$ et al. Antibodies against annexin $\mathrm{V}$ and prothrombin, their correlation with other anti-phospholipid antibodies in recurrent pregnancy loss. J Reprod Contraception 2005; 16: 35-46

20 Tincani A, Spatola M, Cinquioni $M$ et al. Animal models of antiphospholipid syndrome. Rev Rheumat 1998; 65: 614-618

21 World Health Organization. WHO Laboratory Manual for the Examination and Processing of human Semen. 5th ed. Geneva, Switzerland: WHO Press; 2010: 1-286

22 Mackworth-Young CG. Antiphospholipid syndrome: multiple mechanisms. Clin Exp Immunol 2004; 136: 393-401

23 Buyon JP, Petri MA, Kim MY et al. The effect of combined estrogen and progesterone hormone replacement therapy on disease activity in systemic lupus erythematosus: a randomized trial. Ann Intern Med 2005; 142: 953-962

24 Girolami A, Zanon E, Zanardi S et al. Thromboembolic disease developing during oral contraceptive therapy in young females with antiphospholipid antibodies. Blood Coagul Fibrinolysis 1996; 7: 497-501

25 Julkunen H, Kaaja R, Jouhikainen $T$ et al. Malignant hypertension and antiphospholipid antibodies as presenting features of SLE in a young woman using oral contraceptives. Br J Rheumatol 1991; 30: 471-482

26 Duarte C, Inês L. Oral contraceptives and systemic lupus erythematosus: what should we advise to our patients. Acta Reumatol 2010; 35: 133-140

27 Lakasing L, Khamashta MJ. Contraceptive practices in women with systemic lupus erythematosus and/or antiphospholipid syndrome: what advice should we be giving? Fam Plann Reprod Health Care 2001; 27: $7-12$

28 Yazdany J, Trupin L, Kaiser $R$ et al. Contraceptive counseling and use among women with systemic lupus erythematosus: a gap in health care quality? Arthr Care Res 2011; 63: 358-365

29 Lateef A, Petri $M$. Hormone replacement and contraceptive therapy in autoimmune disease. J Autoimmun 2012; 38: J170-J176

30 Bernier MO, Mikaetoff $Y$, Hudson M et al. Combined oral contraceptive use and the risk of systemic lupus erythematosus. Arthr Rheumat 2009; 61: 476-481

31 Devreese KM. Antiphospholipid antibody testing and standardization. Int J Lab Hematol 2014; 36: 352-363

32 Globerson A, Effros RB. Ageing of lymphocytes and lymphocytes in the aged. Immunol Today 2000; 21: 515-521

33 Hradecky L, Subrt I, Ulcova-Gallova Z. Urgent termination of pregnancy in pre-eclampsia and panel of antiphospholipid antibodies. Am J Reprod Immunol 2009; 62: 412-417

34 Kwak-Kim J, Agcaoili MS, Aleta L et al. Management of women with recurrent pregnancy losses and antiphospholipid antibody syndrome. Am J Reprod Immunol 2013; 69: 596-607 